\title{
RAPID DETECTION OF LISTERIA MONOCYTOGENES IN RAW MILK AND SOFT CHEESE BY A REDOX POTENTIAL MEASUREMENT BASED METHOD COMBINED WITH REAL-TIME PCR
}

\author{
Orsolya ERDÖSI*, Katalin SzAKMÁR, Olivér REICHART, Zsuzsanna SzILI, Noémi LÁSZLÓ, \\ Péter SZÉKELY KÖRMÖCZY and Péter LACZAY \\ Department of Food Hygiene, Faculty of Veterinary Science, Szent István University, \\ István u. 2, H-1078 Budapest, Hungary
}

(Received 25 October 2013; accepted 12 March 2014)

The incidence of outbreaks of foodborne listeriosis has indicated the need for a reliable and rapid detection of the microbe in different foodstuffs. A method combining redox potential measurement and real-time polymerase chain reaction (PCR) was developed to detect Listeria monocytogenes in artificially contaminated raw milk and soft cheese. Food samples of $25 \mathrm{~g}$ or $25 \mathrm{ml}$ were homogenised in $225 \mathrm{ml}$ of Listeria Enrichment Broth (LEB) with Oxford supplement, and the redox potential measurement technique was applied. For Listeria species the measuring time was maximum $34 \mathrm{~h}$. The absence of L. monocytogenes could reliably be proven by the redox potential measurement method, but Listeria innocua and Bacillus subtilis could not be differentiated from L. monocytogenes on the basis of the redox curves. The presence of $L$. monocytogenes had to be confirmed by real-time PCR. The combination of these two methods proved to detect $<10 \mathrm{cfu} / \mathrm{g}$ of $L$. monocytogenes in a cost- and time-effective manner. This method can potentially be used as an alternative to the standard nutrient method for the rapid detection of L. monocytogenes in food.

Key words: Listeria monocytogenes, rapid detection, redox potential, realtime PCR, food safety

Listeria monocytogenes is widely distributed in the environment. The microbe can be found in unprocessed food of animal origin such as raw milk, meat, fish as well as fruits and vegetables, but it can also be detected in some processed and ready-to-eat foods, e.g. cheese, ice cream and processed meat, due to postprocessing contamination (Norrung et al., 1999; Guerra et al., 2001). Epidemiological data show that listeriosis has one of the highest hospitalisation and fatality rates among foodborne diseases. Several outbreaks of listeriosis have proved to be associated with the consumption of milk or dairy products, causing great con-

*Corresponding author; E-mail: erdosi.orsolya@aotk.szie.hu; Phone: 0036 (1) 478-4270; Fax: 0036 (1) 478-4155 
cern in the dairy industry due to the number of cases and the nearly $30 \%$ mortality rate of the outbreaks (Newell et al., 2010).

The detection of pathogenic bacteria is a fundamental objective of food microbiology to ensure food safety. Conventional microbiological culture procedures are laborious and time consuming, as they generally require at least 5 days. This time is an off-limited value for screening perishable food products, which is essential if listeriosis outbreaks are to be minimised (Peng and Shelef, 2000).

Although the sensitivity of many modern detection methods has improved significantly, an enrichment step is still needed to overcome the problems of low pathogen numbers and to limit the risk of detecting dead cells (Lantz et al., 1994; Peng and Shelef, 2000; Norton, 2002; O'Grady et al., 2009). The enrichment step is required not only to increase the target pathogen concentration in a sample but also to resuscitate physiologically stressed and injured cells. Selective enrichment is also necessary to suppress the natural background microorganisms as well as to improve the efficiency of detection and to avoid false-negative results (Garrido et al., 2013).

Concerning molecular methods, the sample volume required by the polymerase chain reaction (PCR) technique $(1 \mathrm{ml})$ does not allow the direct determination of the prescribed food safety requirement: 'no L. monocytogenes in $25 \mathrm{~g}$ sample' (Commission Regulation [EC] No 2073/2005 on microbiological criteria for foodstuffs). Before taking a sample for the PCR test, the microbial concentration of the sample had to be increased by selective enrichment in the same way as when using conventional culture methods. The necessity of the enrichment depends on the microbial concentration of the sample and is independent of the kind of PCR kit.

After enrichment, Listeria monocytogenes can be detected by culturing or by PCR. The culture method is time consuming while the PCR is very expensive.

In order to reduce the cost and time requirement of the rapid and reliable detection and identification of $L$. monocytogenes, a redox potential measuring system was chosen for the enrichment, which made it possible to screen the samples potentially infected by $L$. monocytogenes.

The instrumental enrichment method based on redox potential measurement was originally developed and validated for the rapid determination of viable counts of several microorganisms (E. coli, Salmonella, Enterococcus etc.) in water, milk, foods, surface samples, etc. (Reichart et al., 2007; Erdősi et al., 2012).

The aim of the present work was to develop a protocol for the rapid detection of L. monocytogenes in raw milk and soft cheese by the combination of the redox potential measurement method for enrichment and real-time PCR for identification in a simple, time and cost-effective manner.

The basic concept of this combination is that the redox potential measurement, as an enrichment process, could screen the samples which do not contain L. monocytogenes. Only the samples presumably positive for L. monocytogenes need the expensive PCR identification. 
In order to determine the most suitable medium, the selectivity of three standard Listeria enrichment broths was studied. Applying the most suitable medium in redox potential measurements of artificially contaminated milk and cheese samples, the obtained enriched media were directly used in real-time PCR identification of $L$. monocytogenes. The experimental results confirmed the usefulness of the combination of the two methods.

\section{Materials and methods}

\section{Bacterial strains}

Since several bacterial species can co-exist and therefore be detected as 'background' microflora in food samples, in order to investigate the specificity and reliability of the combined method the following bacterial strains were used: Listeria monocytogenes (ATCC 19111, ATCC 7644, NCAIM B1935), L. ivanovii (ATCC 19119), L. innocua (ATCC 33090), Staphylococcus aureus (ATCC 12600), Escherichia coli (ATCC 105369), Bacillus cereus (NCAIM B1827), B. subtilis (NCAIM B1095). Listeria strains were stored and cultured on Brain-Heart Agar (BHA, Merck) and the other bacterial species on Tryptic Soy Agar (TSA, Merck).

\section{Culture media}

In order to choose the most selective culture medium, bacterial growth was monitored by redox potential measurements in three different types of media: (a) Listeria Enrichment Broth (LEB) Base according to FDA/IDF-FIL (Merck) with Oxford Listeria Selective Supplement (Merck); (b) Listeria Enrichment Broth (LEB) Base according to FDA/IDF-FIL (Merck) with Listeria Selective Enrichment Supplement according to FDA-BAM 1995/IDF-FIL (Merck); (c) Fraser Listeria Selective Enrichment Broth (Merck) with Fraser Listeria Supplement (Merck).

\section{Sample preparation}

Twenty-five g of soft cheese or 25-ml raw milk samples were homogenised in $225 \mathrm{ml}$ of the Listeria Enrichment Broth (LEB) Base according to FDA/ IDF-FIL (Merck) with Oxford Listeria Selective Supplement (Merck) which was the most selective for L. monocytogenes among the three media examined. Raw milk and soft cheese samples were obtained from the local market.

The food samples spiked with the test microorganisms were examined at three contamination levels (low, medium and high). From each test microbe a 24-h slant agar single culture was washed with $9 \mathrm{ml}$ peptone water and a tenfold dilution series was prepared. The samples ( $25 \mathrm{~g}$ in $225 \mathrm{ml}$ broth) were inoculated with $1 \mathrm{ml}$ of the 9th, 6th and 1st dilution of the single culture to set the different contamination levels, respectively. The incubation temperature was $37^{\circ} \mathrm{C}$. 
The actual microbial counts of the inocula were determined by plate counting from the dilution series in three parallels and referred to $1 \mathrm{ml}$ or $\mathrm{g}$ of the sample. The coefficient of variation $(\mathrm{CV} \%=15 \%)$ was calculated from the standard deviation of the $\log \mathrm{N}$ values, determined from the residual mean square of the analysis of variance.

Experimental design: 2 products (milk and soft cheese), 8 microbes (natural + 7 test microbes), 3 contamination levels (low, medium, high, EN ISO 16140:2003), 3 parallels, sample size: $\mathrm{n}=144$.

\section{Conventional culturing method}

The conventional culturing method was done as described in ISO 11290-1. The simplified flow diagram of the classical method is demonstrated in Fig. 1.

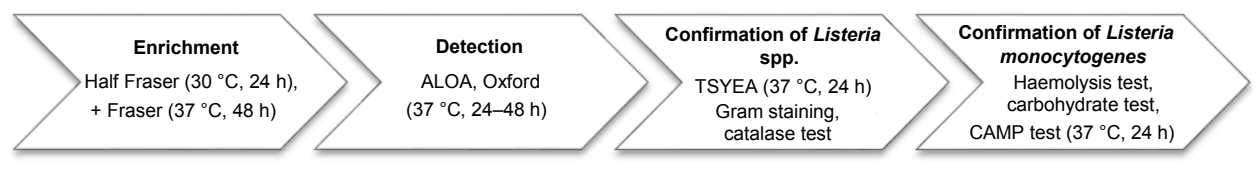

Fig. 1. Simplified flow diagram of the ISO 11290-1 classical method

\section{Redox potential measuring method}

The principle of the method is that in the measuring cell, due to microbial multiplication, above a quite high $\left(10^{6}-10^{7} \mathrm{cfu} / \mathrm{ml}\right)$ critical microbe concentration the redox potential of the medium is well-detectably reduced and the rate of its change exceeds a defined detection criterion. The time to detection (TTD) means the time necessary to reach the detection criterion.

There is a close linear correlation between the TTD and the logarithm of the initial viable count. This relationship is represented by the calibration curve that makes it possible to calculate the initial viable microbe concentration as a function of the TTD.

The measuring system records the redox curve, determines the TTD and calculates the initial viable count of the sample on the basis of the calibration curve. The method provides a good estimation of the microbial contamination level. Beyond the selectivity of the medium, owing to the characteristic pattern of the redox curves, the system usually makes it possible to identify the growing microflora (Reichart et al., 2007).

The determinations were carried out using the MicroTester, a 32-channel redox potential measuring instrument. The MicroTester system consists of the following parts: water bath thermostat (accuracy: $\pm 0.2{ }^{\circ} \mathrm{C}$ ), test cells, which in this case were 250-ml screw-capped glass flasks equipped with Schott Blue Line $31 \mathrm{RX}$ redox electrodes, PC drive (Windows XP, special software) data collection and evaluating unit, monitor. 


\section{Real-time PCR method}

The redox potential measurement, as an enrichment process, could screen the samples which did not contain $L$. monocytogenes. Only the presumably $L$. monocytogenes-positive samples were investigated further by real-time PCR to identify the bacterium.

Genomic DNA was isolated from $1 \mathrm{ml}$ of enriched food sample using the Mericon DNA Bacteria Plus Kit (Qiagen) according to the manufacturer's instructions. Due to the loss during the process, $100 \mu \mathrm{l}$ of the DNA isolate contains $25 \%$ of the total DNA originating from a $1-\mathrm{ml}$ sample of the enrichment culture. DNA (isolate) $=0.25 \cdot$ DNA (sample) .

Real-time PCR amplification was performed in SLAN ${ }^{\circledR}$ Real-Time PCR System (Hongshi) using the Mericon L. monocytogenes Kit (Qiagen) designed for the qualitative detection of L. monocytogenes in food and animal feed after enrichment. PCR was done in a final volume of $20 \mu \mathrm{l}$ including $9.2 \mu \mathrm{l}$ DNA isolate and $10.8 \mu \mathrm{l}$ Multiplex PCR Master Mix containing target-specific primers and probes, as well as the internal control. DNA $(\mathrm{PCR})=0.092 \cdot \mathrm{DNA}$ (isolate).

Detection limit: the assay can detect down to 10 copies of $L$. monocytogenes DNA in a reaction (Mericon, 2011), which - by calculation - provides 435 DNS copies/ml sample.

Detection of pathogens using real-time PCR was based on the amplification of a specific region of the relevant pathogen genome. The amplified product was detected by using target-specific fluorescent probes. As the PCR product accumulated, there was an increased fluorescent signal from the bound probes. Monitoring the fluorescence intensities during the PCR run (i.e. in real time) allowed the detection of the accumulating PCR product without the need to reopen the reaction tubes afterward. A positive result is visible as a final point of the fluorescence curve that lies clearly above the threshold. The number of cycles belonging to this point is the quantification cycle value. As a guideline, the uninhibited internal control should give a quantification cycle value ranging between 28 and 32. A quantification cycle value over 33 indicates inhibition. If there is no visible point till the 38th cycle ( $\mathrm{CT} \geq 38$ ), the result is negative. The isolated pure bacterial DNA was assayed using a streamlined real-time PCR protocol.

\section{Results}

\section{Examination of the selectivity of media}

Bacterial growth was monitored by redox potential measurements in three different types of media at $37{ }^{\circ} \mathrm{C}$. Each culture medium $(250 \mathrm{ml})$ was inoculated with $1 \mathrm{ml}$ (about $10^{6} \mathrm{cfu}$ ) of the single culture of the test microorganism. 
(a) Fraser Listeria Selective Enrichment Broth (Merck) with Fraser Listeria Supplement (Merck). Growth: All of the three L. monocytogenes strains, $L$. ivanovii, L. innocua, E. coli, Staphylococcus aureus.

(b) Listeria Enrichment Broth (LEB) Base according to FDA/IDF-FIL (Merck) with Listeria Selective Enrichment Supplement according to FDA-BAM 1995/IDF-FIL (Merck). Growth: All of the three L. monocytogenes strains, $L$. ivanovii, L. innocua, S. aureus. No growth: E. coli.

(c) Listeria Enrichment Broth (LEB) Base according to FDA/IDF-FIL (Merck) with Oxford Listeria Selective Supplement (Merck). Growth: All of the three L. monocytogenes strains, L. innocua. No growth: L. ivanovii, E. coli. Inhibited: S. aureus.

As can be seen, the LEB with Oxford Listeria Selective Supplement (Merck) showed the highest selectivity for the detection of L. monocytogenes; therefore, this medium was used for testing the samples prepared. The selectivity of the LEB broth with Oxford selective supplement is demonstrated in Fig. 2.

Considering that $E$. coli was totally inhibited and the partially inhibited $S$. aureus did not reduce the redox potential of the medium to the level of Listeria spp., in the presence of L. monocytogenes or L. innocua the characteristic shape of Listeria redox curves could be recognised. In the presence of Bacillus subtilis the redox potential drops below the level of Listeria spp., so in this case the presence of $L$. monocytogenes could not be excluded (Fig. 2).

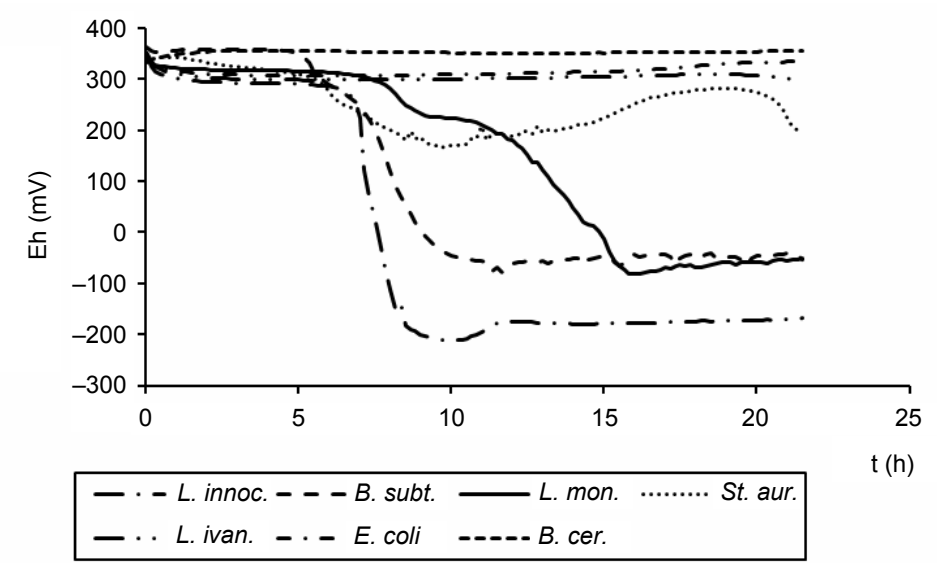

Fig. 2. Selectivity of LEB broth with Oxford selective supplement. Eh: redox potential (mV), $\mathrm{T}=37^{\circ} \mathrm{C}$

Based on the redox potential measurement, the LEB with Oxford supplement was the most selective medium for L. monocytogenes, but the redox curves of the three Listeria spp. and B. subtilis could not be differentiated. Due to this disability of differentiation, the identification had to be performed in each case 
when the presence of $L$. monocytogenes could not be excluded. Real-time PCR technique was used to confirm the presence of L. monocytogenes.

\section{Determination of calibration curves of Listeria spp.}

The redox potential measurements were performed in LEB with Oxford supplement. For the determination of the calibration curve a slant agar of the Listeria strain was washed down and a tenfold dilution series was prepared with peptone water to the 6th dilution level. From each dilution $1 \mathrm{ml}$ was pipetted into a redox measuring cell containing $250 \mathrm{ml}$ LEB with Oxford supplement. The equipment automatically determined the detection times belonging to the different dilution levels. After inputting the viable count of the undiluted inoculum (determined by plate counting), the software computed the calibration curve. The equations of the calibration curves were calculated by linear regression from the logarithm of the initial viable cell numbers in the measuring cells $(\log N)$ and the TTD values. The measurement of the three L. monocytogenes strains (1: ATCC 19111, 2: ATCC 7644, 3: NCAIM B1935) resulted in a common calibration curve which significantly differed from the calibration curve of L. innocua (Fig. 3).

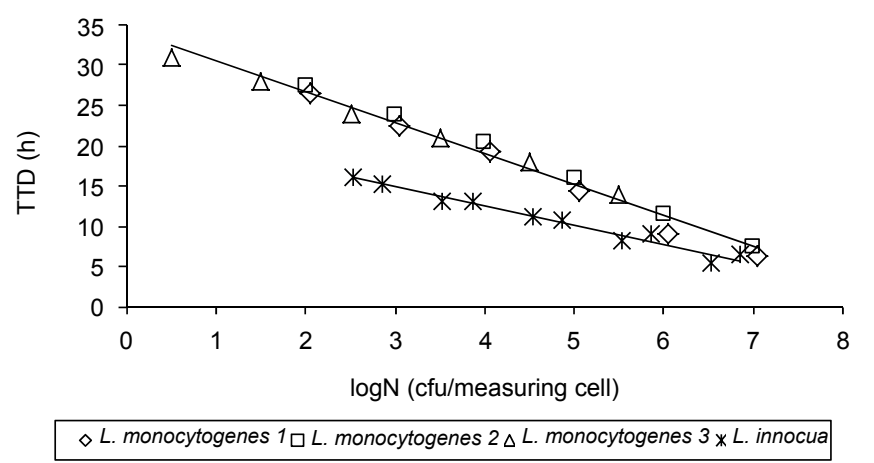

Fig. 3. Calibration curves of Listeria spp. in LEB broth with Oxford supplement. TTD: Time to Detection where the detection criterion was $-0.5 \mathrm{mV} / \mathrm{min}$

As demonstrated in Fig. 3, it could be established that the growth rate of $L$. monocytogenes was lower (the TTD belonging to the same $\log \mathrm{N}$ is higher) than that of L. innocua .

The detailed mathematical-statistical evaluation of the L. monocytogenes regression was performed by Excel regression analysis. The main results are as follow: Equation: TTD $(\mathrm{h})=34.32-3.822 \cdot \log \mathrm{N} ; \mathrm{R}^{2}=0.9844$, data pairs, $\mathrm{n}=18$; SD $(\mathrm{TTD})=0.9455 \mathrm{~h}$; intercept, TTD $(0)=34.32 \mathrm{~h}, 95 \%$ confidence interval: 33.19 35.44; Slope $=-3.822 \mathrm{~h} / 1 \log$ unit, $95 \%$ confidence interval: -4.077 to -3.567 .

The validation characteristics calculated from the regression curve are as follow: Linearity: valid in the total range of detection; sensitivity (the slope of 
the calibration curve): $3.82 \mathrm{~h} / \log$ unit; detection limit: theoretically 1 living microbe in the test cell; range of detection: $10^{0}-10^{7} \mathrm{cfu} / \mathrm{ml}$; repeatability of the TTD values: $\mathrm{SD}(\mathrm{TTD})=0.9455 \mathrm{~h}$.

Determination of the absence or presumable presence of $\mathrm{L}$. monocytogenes by the redox potential method

Raw milk and soft cheese samples were tested by the redox potential method for the absence or presumable presence of L. monocytogenes.

The theoretical time requirement of detection of one target microorganism in the measuring cell $(\log N=0)$ can be calculated from the intercept TTD $(0)$ of the calibration curve.

Completing the calculation for the slower-growing L. monocytogenes and taking into account the upper limit of the intercept (35.44 h), if we do not obtain a TTD within $36 \mathrm{~h}$, it is highly probable that the inoculum of the measuring cell is free of $L$. monocytogenes.

The time required for screening the L. monocytogenes-negative samples is $36 \mathrm{~h}$. In the case of detectable contamination this time significantly decreases. Getting a TTD value means a presumably positive sample. To confirm the presence of L. monocytogenes, real-time PCR technique was used. Obtaining a TTD value indicated that the microbe concentration in the test cell reached about $10^{6} \mathrm{cfu} / \mathrm{ml}$, and thus the same suspension was ready for direct DNA isolation and real-time PCR assay.

Identification of $\mathrm{L}$. monocytogenes from presumably positive samples by $P C R$

Identification from the enriched suspension by real-time PCR required another $3 \mathrm{~h}$. Due to the specificity of the Mericon L. monocytogenes Kit, only those samples were found to be positive which had been spiked with L. monocytogenes. Those samples, which were suspected to contain L. monocytogenes on the basis of redox potential measurement but actually were spiked with $L$. innocua or $B$. subtilis, were found to be negative in each parallel of all dilutions.

The results of the spiked samples (positive or negative) as well as the time requirement of the redox potential measurements and real-time PCR and their combination compared to the conventional ISO 11290-1 standard method are summarised in Tables $1-3$.

\section{Discussion}

Listeria monocytogenes is a widely occurring environmental and foodborne pathogenic microbe capable of causing even lethal disease in humans. The presence of $L$. monocytogenes in several foodstuffs and the increasing number of outbreaks all over the world indicate the need for a faster detection of L. monocytogenes. Molecular methods such as the PCR can rapidly detect and identify 
foodborne pathogenic microbes (Rijpens and Herman, 2002). Among the different PCR methods the sensitivity of real-time PCR is equal to that of the culture methods (Navas et al., 2006). However, the use of PCR may be limited by its cost or the sample volume (Rodríguez-Lázaro et al., 2004).

Table 1

Detection and identification of Listeria monocytogenes at low contamination level

\begin{tabular}{|c|c|c|c|c|c|c|c|}
\hline \multirow{2}{*}{ Method } & \multirow{2}{*}{$\begin{array}{c}\mathrm{N} \\
(\mathrm{cfu} / \mathrm{ml})\end{array}$} & \multirow{2}{*}{$\begin{array}{c}\text { Standard } \\
\text { result }\end{array}$} & \multicolumn{2}{|c|}{ Redox potential } & \multicolumn{2}{|c|}{ Real-time PCR } & \multirow{2}{*}{$\begin{array}{l}\text { Total time } \\
\text { (h) }\end{array}$} \\
\hline & & & result & TTD (h) & result & time $(\mathrm{h})$ & \\
\hline Milk & & --- & --- & $<36$ & & - & 36 \\
\hline L. monocytogenes & $2.1 \cdot \times 10^{0}$ & +++ & +++ & 31 & +++ & 3 & 34 \\
\hline L. ivanovii & $4.1 \cdot \times 10^{0}$ & --- & --- & $<36$ & & - & 36 \\
\hline L. innocua & $3.3 \cdot \times 10^{0}$ & --- & +++ & 20 & --- & 3 & 23 \\
\hline Staphylococcus aureus & $4.2 \cdot \times 10^{0}$ & --- & --- & $<36$ & & - & 36 \\
\hline Escherichia coli & $5.6 \cdot \times 10^{0}$ & --- & --- & $<36$ & & - & 36 \\
\hline Bacillus cereus & $1.5 \cdot \times 10^{0}$ & --- & --- & $<36$ & & & 36 \\
\hline Bacillus subtilis & $2.5 \cdot \times 10^{0}$ & --- & +++ & 25 & --- & 3 & 28 \\
\hline Soft cheese & & --- & --- & $<36$ & & - & 36 \\
\hline L. monocytogenes & $9.5 \cdot \times 10^{0}$ & +++ & +++ & 29 & +++ & 3 & 32 \\
\hline L. ivanovii & $3.6 \times \cdot 10^{0}$ & --- & --- & $<36$ & & - & 36 \\
\hline L. innocua & $5.7 \times \cdot 10^{0}$ & --- & +++ & 21 & --- & 3 & 24 \\
\hline Staph. aureus & $6.3 \times \cdot 10^{0}$ & --- & --- & $<36$ & & - & 36 \\
\hline E. coli & $2.1 \times \cdot 10^{0}$ & --- & --- & $<36$ & & - & 36 \\
\hline Bacillus cereus & $2.1 \times \cdot 10^{0}$ & --- & --- & $<36$ & & - & 36 \\
\hline Bacillus subtilis & $3.1 \times \cdot 10^{0}$ & --- & +++ & 24 & --- & 3 & 27 \\
\hline
\end{tabular}

$\mathrm{N}$ : microbe concentration of the inoculum, mean of 3 parallels, $\mathrm{CV}(\mathrm{N})= \pm 15 \%$; Total: Total time requirement of identification, Redox + PCR; Standard: ISO 11290-1; TTD: Time to Detection, $\mathrm{SD}(\mathrm{TTD})=0.95 \mathrm{~h}$

In this study, it was demonstrated that rapid and reliable detection of $L$. monocytogenes in raw milk and soft cheese was possible by a combination of redox potential measurement and real-time PCR. In order to detect low numbers (even one cell) of bacteria and resuscitate physiologically stressed and injured ones, the enrichment phase was a crucial step (Cocolin et al., 2002). During the enrichment phase the L. monocytogenes-containing (i.e. presumably positive) samples could be screened by the redox potential measurement technique. Since the redox potential method was not able to distinguish the other Listeria spp. and $B$. subtilis from each other, the positive samples needed further identification by real-time PCR.

The first step of the study was to select the most suitable medium, which proved to be LEB with Oxford supplement. In this selective medium the growth of $L$. ivanovii could not be detected by the redox method. Supposedly, this is the consequence of yet undefined interactions of the components and their concen- 
trations, with special regard to the antibiotics. Earlier, direct differentiation of $L$. monocytogenes from other Listeria spp. proved to be impossible with diverse types of media used by the conventional methods (Jamali et al., 2013).

Table 2

Detection and identification of Listeria monocytogenes at medium contamination level

\begin{tabular}{|c|c|c|c|c|c|c|c|}
\hline \multirow{2}{*}{ Method } & \multirow{2}{*}{$\begin{array}{c}\mathrm{N} \\
(\mathrm{cfu} / \mathrm{ml})\end{array}$} & \multirow{2}{*}{$\begin{array}{c}\text { Standard } \\
\text { result }\end{array}$} & \multicolumn{2}{|c|}{ Redox potential } & \multicolumn{2}{|c|}{ Real-time PCR } & \multirow{2}{*}{$\begin{array}{l}\text { Total time } \\
\text { (h) }\end{array}$} \\
\hline & & & result & TTD (h) & result & time $(\mathrm{h})$ & \\
\hline Milk & & --- & --- & $<36$ & & - & 36 \\
\hline L. monocytogenes & $2.2 \cdot \times 10^{3}$ & +++ & +++ & 22 & +++ & 3 & 25 \\
\hline L. ivanovii & $3.5 \times \cdot 10^{3}$ & --- & --- & $<36$ & & - & 36 \\
\hline L. innocua & $9.8 \times \cdot 10^{3}$ & --- & +++ & 15 & --- & 3 & 18 \\
\hline Staphylococcus aureus & $5.6 \times \cdot 10^{3}$ & --- & --- & $<36$ & & - & 36 \\
\hline Escherichia coli & $2.4 \times \cdot 10^{3}$ & --- & --- & $<36$ & & - & 36 \\
\hline Bacillus cereus & $2.4 \times \cdot 10^{3}$ & --- & --- & $<36$ & & - & 36 \\
\hline Bacillus subtilis & $3.6 \times \cdot 10^{3}$ & --- & +++ & 17 & --- & 3 & 20 \\
\hline Soft cheese & & --- & --- & $<36$ & & - & 36 \\
\hline L. monocytogenes & $5.4 \times \cdot 10^{3}$ & +++ & +++ & 21 & +++ & 3 & 24 \\
\hline L. ivanovii & $3.1 \times \cdot 10^{3}$ & --- & --- & $<36$ & & - & 36 \\
\hline L. innocua & $2.5 \times \cdot 10^{3}$ & --- & +++ & 14 & --- & 3 & 17 \\
\hline Staph. aureus & $4.1 \times \cdot 10^{3}$ & --- & --- & $<36$ & & - & 36 \\
\hline E. coli & $3.4 \times \cdot 10^{3}$ & --- & --- & $<36$ & & - & 36 \\
\hline Bacillus cereus & $5.3 \times \cdot 10^{3}$ & --- & --- & $<36$ & & - & 36 \\
\hline Bacillus subtilis & $4.2 \times \cdot 10^{3}$ & --- & +++ & 16 & --- & 3 & 19 \\
\hline
\end{tabular}

$\mathrm{N}$ : microbe concentration of the inoculum, mean of 3 parallels, $\mathrm{CV}(\mathrm{N})= \pm 15 \%$; Total: Total time requirement of identification, Redox + PCR; Standard: ISO 11290-1; TTD: Time to Detection, $\mathrm{SD}(\mathrm{TTD})=0.95 \mathrm{~h}$

From the calibration curves of the redox potential measurement it could be deducted that in the presence of $L$. monocytogenes the result is obtained within maximum $36 \mathrm{~h}$. If we get no TTD within $36 \mathrm{~h}$, the sample is probably free of $L$. monocytogenes contamination. The proposed combination of redox potential measurement with PCR was applied to detect L. monocytogenes in raw milk and soft cheese samples artificially contaminated with listeria and disturbing bacterium species. The testing of samples at three contamination levels (Tables 1-3) showed no differences between the different spiking concentrations. Only the samples containing L. monocytogenes proved to be positive (Tables 1-3).

The standard microbiological method always detected the presence of $L$. monocytogenes without false positive or negative results. The redox potential method detected the presence of $L$. monocytogenes and gave false positive results in the presence of $L$. innocua or B. subtilis but did not give false negative results. Direct PCR investigation of the presumably positive suspension of redox poten- 
tial measurement always distinguished the presence of $L$. monocytogenes from the disturbing microbes without any false result.

The results obtained by the combination of the two instrumental methods were completely identical with those of the classical culture methods. However, the time requirement of the investigations was significantly shorter. At low contamination levels $(\mathrm{N}<10 \mathrm{cfu} / \mathrm{g}$, Table 1$)$ below the detection limit of the direct PCR technique (Rantsiou et al., 2008; Martin et al., 2012), the detection of $L$. monocytogenes required $34 \mathrm{~h}$ including the redox potential and PCR methods. At medium contamination level $\left(10^{3}-10^{4} \mathrm{cfu} / \mathrm{g}\right.$, Table 2$)$ the instrumental detection and identification needs about $24 \mathrm{~h}$. At extremely high contamination $\left(10^{7}-10^{8} \mathrm{cfu} / \mathrm{g}\right.$, Table 3 ) the time requirement is about $8 \mathrm{~h}$.

Table 3

Detection and identification of Listeria monocytogenes at high contamination level

\begin{tabular}{|c|c|c|c|c|c|c|c|}
\hline \multirow{2}{*}{ Method } & \multirow{2}{*}{$\begin{array}{c}\mathrm{N} \\
(\mathrm{cfu} / \mathrm{ml})\end{array}$} & \multirow{2}{*}{$\begin{array}{l}\text { Standard } \\
\text { result }\end{array}$} & \multicolumn{2}{|c|}{ Redox potential } & \multicolumn{2}{|c|}{ Real-time PCR } & \multirow{2}{*}{$\begin{array}{l}\text { Total time } \\
\text { (h) }\end{array}$} \\
\hline & & & result & $\overline{\text { TTD (h) }}$ & result & time (h) & \\
\hline Milk & & --- & --- & $<36$ & & - & 36 \\
\hline L. monocytogenes & $8.9 \times \cdot 10^{7}$ & +++ & +++ & 4.4 & +++ & 3 & 7.4 \\
\hline L. ivanovii & $8.5 \times \cdot 10^{8}$ & --- & --- & $<36$ & & - & 36 \\
\hline L. innocua & $5.1 \times \cdot 10^{8}$ & --- & +++ & 2.3 & --- & 3 & 5.3 \\
\hline Staphylococcus aureus & $3.2 \times \cdot 10^{8}$ & --- & --- & $<36$ & & - & 36 \\
\hline Escherichia coli & $4.1 \times \cdot 10^{8}$ & --- & --- & $<36$ & & - & 36 \\
\hline Bacillus cereus & $1.6 \times \cdot 10^{8}$ & --- & --- & $<36$ & & & 36 \\
\hline Bacillus subtilis & $6.3 \times \cdot 10^{8}$ & --- & +++ & 5 & --- & 3 & 8 \\
\hline Soft cheese & & --- & --- & $<36$ & & - & 36 \\
\hline L. monocytogenes & $3.5 \times \cdot 10^{7}$ & +++ & +++ & 4.6 & +++ & 3 & 7.6 \\
\hline L. ivanovii & $8.3 \times \cdot 10^{7}$ & --- & --- & $<36$ & & - & 36 \\
\hline L. innocua & $6.4 \times \cdot 10^{7}$ & --- & +++ & 4.1 & --- & 3 & 7.1 \\
\hline Staph. aureus & $5.6 \times \cdot 10^{8}$ & --- & --- & $<36$ & & - & 36 \\
\hline E. coli & $2.4 \times \cdot 10^{8}$ & --- & --- & $<36$ & & - & 36 \\
\hline Bacillus cereus & $1.9 \times \cdot 10^{8}$ & --- & --- & $<36$ & & & 36 \\
\hline Bacillus subtilis & $5.9 \times \cdot 10^{8}$ & --- & +++ & 4.5 & --- & 3 & 7.5 \\
\hline
\end{tabular}

$\mathrm{N}$ : microbe concentration of the inoculum, mean of 3 parallels, $\mathrm{CV}(\mathrm{N})= \pm 15 \%$; Total: Total time requirement of identification, Redox + PCR; Standard: ISO 11290-1; TTD: Time to Detection, $\mathrm{SD}(\mathrm{TTD})=0.95 \mathrm{~h}$

As compared to the conventional culture method which requires $120 \mathrm{~h}$ for the detection of 'no Listeria' or $168 \mathrm{~h}$ for 'no L. monocytogenes' (ISO 11290-1, 1996), having the results by the proposed method couple in maximum 36 hours would provide a significant aid to the manufacturers to reliably determine the criterion that $L$. monocytogenes is not present in $25 \mathrm{~g}$ sample before the product leaves the production plant. 
The redox potential measurement as an enrichment process was able to screen the majority of the L. monocytogenes-negative samples. Only the presumably positive samples need the expensive PCR identification. The benefit of the combined method is that in case of L. monocytogenes-negative samples the cost of the PCR identification can be saved.

\section{Acknowledgement}

This work was supported by the research project TÁMOP-4.2.1.B-11/2/KMR-20110003.

\section{References}

Cocolin, L., Rantsiou, K., Iacumin, L., Cantoni, C. and Comi, G. (2002): Direct identification in food samples of Listeria spp. and Listeria monocytogenes by molecular methods. App. Environ. Microbiol. 68, 6273-6282.

Commission Regulation (EC) No 2073/2005 of 15 November 2005 on microbiological criteria for foodstuffs. Official Journal of the European Union, L 338.

EN ISO 16140:2003. Microbiology of food and animal feeding stuffs. Protocol for the validation of alternative methods.

Erdősi, O., Szakmár, K., Reichart, O., Székely-Körmöczy, P. and Laczay, P. (2012): Application of the redox potential measurement based rapid method in the microbial hygienic control. Acta Aliment. Hung. 41, 45-55.

Garrido, A., Chapela, M., Román, B., Fajardo, P., Lago, J. and Vieites, J. M. (2013): A new multiplex real-time PCR developed method for Salmonella spp. and Listeria monocytogenes detection in food and environment samples. Food Control 31, 76-85.

Guerra, M., McLauchin, J. and Bernardo, F. A. (2001): Listeria in ready-to-eat and unprocessed foods produced in Portugal. Food Microbiol. 18, 423-429.

ISO 11290-1:1996. Microbiology of food and animal feeding stuffs. Horizontal method for the detection and enumeration of Listeria monocytogenes. Part 1: Detection method.

Jamali, H., Chai, L. C. and Thong, K. L. (2013): Detection and isolation of Listeria spp. and Listeria monocytogenes in ready-to-eat foods with various selective culture media. Food Control 32, 19-24.

Lantz, P. G., Hahnhagerdal, B. and Radstrom, P. (1994): Sample preparation methods in PCRbased detection of food pathogens. Trends Food Sci. Technol. 5, 384-389.

Martin, B., Garriga, M. and Aymerich, T. (2012): Pre-PCR treatments as a key factor on the probability of detection of Listeria monocytogenes and Salmonella in ready-to-eat meat products by real-time PCR. Food Control 27, 163-169.

Mericon Pathogen Detection Handbook (2011): p. 13.

Navas, J., Ortiz, S., Lopez, P., Jantzen, M., Lopez, M. and Martinez-Ruarez, J. V. (2006): Evaluation of effects of primary and secondary enrichment for the detection of Listeria monocytogenes by real-time PCR in retail ground chicken meat. Foodborne Pathog. Dis. 3, 347-354.

Newell, D. G., Koopmans, M., Verhoef, L., Duizer, E., Aidara-Kane, A., Sprong, H., Opsteegh, M., Langelaar, M., Threfall, J., Scheutz, F., van der Giessen, J. and Kruse, H. (2010): Food-borne diseases - The challenges of 20 years ago still persist while new ones continue to emerge. Int. J. Food Microbiol. 139, S3-S15.

Norrung, B., Anderson, J. K. and Schlundt, J. (1999): Incidence and control of Listeria monocytogenes in foods in Denmark. Int. J. Food Microbiol. 53, 195-203. 
Norton, D. (2002): Polymerase chain reaction-based methods for detection of Listeria monocytogenes: toward real-time screening for food and environmental samples. J. AOAC Int. 85, $505-515$.

O’Grady, J., Ruttledge, M., Sedano-Balbás, S., Smith, T. J., Barry, T. and Maher, M. (2009): Rapid detection of Listeria monocytogenes in food using culture enrichment combined with realtime PCR. Food Microbiol. 26, 4-7.

Peng, H. and Shelef, L. A. (2000): Rapid detection of low levels of Listeria in foods and next day confirmation of L. monocytogenes. J. Microbiol. Methods 41, 113-120.

Rantsiou, K., Alessandria, V., Urso, R., Dolci, P. and Cocolin, L. (2008): Detection, quantification and vitality of Listeria monocytogenes in food as determined by quantitative PCR. Int. J. Food Microbiol. 121, 99-105.

Reichart, O., Szakmár, K., Jozwiak, Á., Felföldi, J. and Baranyai, L. (2007): Redox potential measurement as a rapid method for microbiological testing and its validation for coliform determination. Int. J. Food Microbiol. 114, 143-148.

Rijpens, N. P. and Herman, L. M. (2002): Molecular methods for identifications and detection of bacterial food pathogens. J. AOAC Int. 85, 984-995.

Rodríguez-Lázaro, D., Hernández, M. and Pla, M. (2004): Simultaneous quantitative detection of Listeria spp. and Listeria monocytogenes using a duplex real-time PCR-based assay. FEMS Microbiol. Lett. 233, 257-267. 